\title{
Protease-activated receptors and inflammatory hyperalgesia
}

\section{Nathalie Vergnolle}

Department of Pharmacology and Therapeutics, Faculty of Medicine, University of Calgary, 3330 Hospital Drive NW Calgary, T2N4N1, Canada

Recent advances in basic science pointed to a role for proteinases, through the activation of proteinase-activated receptors (PARs) in nociceptive mechanisms. Activation of PAR,$P A R_{2}$ and $P A R_{4}$ either by proteinases or by selective agonists causes inflammation inducing most of the cardinal signs of inflammation: swelling, redness, and pain. Sub-inflammatory doses of PAR 2 agonist still induced hyperalgesia and allodynia while PAR 2 has been shown to be implicated in the generation of hyperalgesia in different inflammatory models. In contrast, sub-inflammatory doses of PAR $R_{1}$ increases nociceptive threshold, inhibiting inflammatory hyperalgesia, thereby acting as an analgesic agent. PARs are present and functional on sensory neurons, where they participate either directly or indirectly to the transmission and/or inhibition of nociceptive messages. Taken together, the results discussed in this review highlight proteinases as signaling molecules to sensory nerves. We need to consider proteinases and the receptors that are activated by proteinases as important potential targets for the development of analgesic drugs in the treatment of inflammatory pain.

Key words: proteases - inflammation - pain - thrombin - trypsin - tryptase

Proteases can signal to cells through a variety of mechanisms. They can transform a pro-receptor or a proagonist into an active receptor or agonist respectively, by cleaving these molecules. They can act as any other agonist by binding to a receptor through their non-catalytic sites. Compelling evidence that has accumulated in recent years also indicates that certain proteases, such as thrombin, tryptase, and trypsin, can signal to cells through the activation of protease-activated receptors (PARs). PARs are activated by a unique mechanism that involves the proteolytic cleavage of their N-terminal extracellular domain. This cleavage, due to the action of diverse proteases, releases a new $\mathrm{N}$-terminal domain that acts as a tethered ligand, binding the receptor itself on its second extracellular loop, to induce an intracellular signal (Fig. 1). Four members of the PARs family have been cloned. $\mathrm{PAR}_{1}, \mathrm{PAR}_{3}$ and $\mathrm{PAR}_{4}$ are considered as thrombin receptors since they have been shown to be responsible for thrombin-induced platelet activation. However, these receptors can also be activated by other proteases such as trypsin and cathepsin $\mathrm{G}$ for $\mathrm{PAR}_{4}$, coagulation factors $\mathrm{Xa}$ and VIIa for $\mathrm{PAR}_{1}$ (Fig. 1). Another member of this family, $\mathrm{PAR}_{2}$, is not activated by thrombin, but can be activated by trypsin and mast cell tryptase. Useful pharmacological tools have been raised to specifically activate those receptors: small synthetic peptides corresponding to the tethered ligand domain are able to activate selectively $\mathrm{PAR}_{1}, \mathrm{PAR}_{2}$ and $\mathrm{PAR}_{4}$. Surprinsingly, $\mathrm{PAR}_{3}$ cannot be activated by peptidic sequences corresponding to its tethered ligand domain, rendering the study of the physiological role of this receptor more difficult in the

E-mail: nvergnol@ucalgary.ca

Received 8 November 2004

Accepted30 December 2004 absence of selective agonist. The peptidic sequence corresponding to the human $\mathrm{PAR}_{2}$ receptor, SLIGKV-NH (where each letter correspond to the amino acid code), selectively activates the receptor (Fig. 1), as does the SLIGRL-NH $\mathrm{N}_{2}$ peptide corresponding to the rat sequence. The tethered ligand sequence corresponding to the human $\mathrm{PAR}_{1}$ receptor (SFLLR-NH $\mathrm{NH}_{2}$; Fig. 1) is not selective for $\mathrm{PAR}_{1}$, but can also activate $\mathrm{PAR}_{2}$. A substitution of the serine amino acid by a threonine (TFLLR-NH ${ }_{2}$ ) remarkably increases the specificity of the peptide for the $\mathrm{PAR}_{1}$ receptor, and this later peptide is now used as a selective $\mathrm{PAR}_{1}$ agonist. Peptide corresponding to the tethered ligand of $\mathrm{PAR}_{4}\left(\mathrm{GYPGKV}-\mathrm{NH}_{2}\right.$; Fig. 1) is specific for $\mathrm{PAR}_{4}$, but is not a very potent agonist. Substitution of the first amino acid by an Alanine residue (AYPGKV-NH ${ }_{2}$ ) considerably increases the potency of the agonist for $\mathrm{PAR}_{4}$ activation and is now preferably used as a PAR agonist.

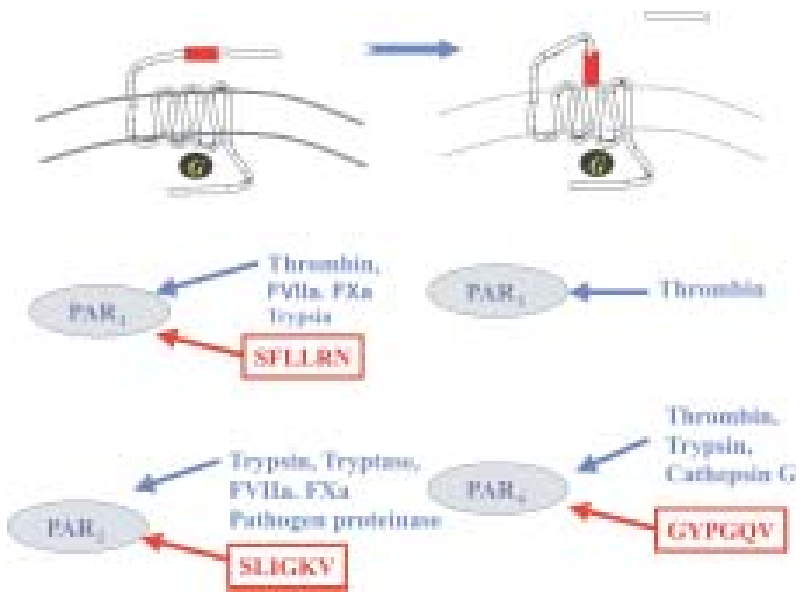

Fig. 1: mechanism of activation of proteinase-activated receptors (PARs) by proteinases, four members of the family: $\mathrm{PAR}_{1}, \mathrm{PAR}_{2}$, $\mathrm{PAR}_{3}$ and $\mathrm{PAR}_{4}$, proteinases responsibles for PARs activation (in blue) and tethered ligand peptidic sequences (red boxes) that can be use to activate each receptor. 


\section{PARs and inflammation}

Several studies have shown the pro-inflammatory effects of acute activation of $\mathrm{PAR}_{2}$. First, we have shown that intraplantar injection of the selective $\mathrm{PAR}_{2}$-activating peptide SLIGRL- $\mathrm{NH}_{2}$ caused edema and inflammatory cell recruitment (Vergnolle et al. 1999a). Later, we have demonstrated that $\mathrm{PAR}_{2}$ activation promotes the first signals for leukocyte recruitment to the site of inflammation, causing leukocyte rolling, adhesion and translocation across the wall of blood vessels (Vergnolle 1999). In the skin, acute activation of $\mathrm{PAR}_{2}$ leads to skin inflammation and $\mathrm{PAR}_{2}$ activation has been implicated in the generation of inflammatory signs associated with contact dermatitis (Seeliger et al. 2003). A recent study by Ferrell et al. (2003), has also demonstrated a prominent role for $\mathrm{PAR}_{2}$ in an animal model of monoarthritis, $\mathrm{PAR}_{2}$-deficient mice did not developed signs of chronic inflammation. In the gut, acute activation of $\mathrm{PAR}_{2}$ caused colitis characterized by gut wall edema, granulocyte recruitment, increased permeability and release of pro-inflammatory cytokines such as interleukin-1 and TNF- $\alpha$ (Cenac et al. 2002). In the airways, the role of $\mathrm{PAR}_{2}$ is controversial. Although studies have shown that $\mathrm{PAR}_{2}$-activating peptides caused relaxation of isolated airways and was protective against bronchoconstrictor challenge (Cocks et al. 1999), other studies have shown that mice that lack functional $\mathrm{PAR}_{2}$ showed extensive allergic response compared to wild-type mice, suggesting a prominent pro-inflammatory role for $\mathrm{PAR}_{2}$ activation in airway diseases (Schmidlin et al. 2002). Similar controversies also exist in the gut, where chronic and systemic treatment with $\mathrm{PAR}_{2}$ agonist was protective against a chronic model of inflammatory bowel disease (Fiorucci et al. 2001), while acute activation of $\mathrm{PAR}_{2}$ in colonic tissues led to inflammation (Cenac et al. 2002). Overall, $\mathrm{PAR}_{2}$ is present in many cells involved in inflammation (endothelial cells, mast cells, neutrophils, eosinophils, epithelium, etc.), and its activation on those cells provokes the release of many inflammatory mediators (prostaglandins, nitric oxide, cytokines, etc.), further supporting the idea that $\mathrm{PAR}_{2}$ activation plays a prominent role in inflammatory pathologies (Vergnolle 2000, 2001b).

Several studies have also shown a pro-inflammatory role for PAR ${ }_{1}$ activation (Cirino et al. 1996, Vergnolle et al. 1999b), and most recently, we have demonstrated that $\mathrm{PAR}_{4}$ agonists induced oedema and granulocyte infiltration when injected into the rat paw (Hollenberg et al. 2004).

\section{PARs on sensory neurons}

Investigating the mechanisms of $\mathrm{PAR}_{2}$-induced inflammation, we have discovered that the receptor was present on sensory nerves, where its activation was able to cause the release of neuropeptides such as substance $\mathrm{P}$ and CGRP (Steinhoff et al. 2000). This $\mathrm{PAR}_{2}$-induced neuropeptide release was responsible for the edema observed after intraplantar injection of $\mathrm{PAR}_{2}$ agonists, but not for granulocyte recruitment to the site of inflammation (Steinhoff et al. 2000). Other studies have shown that the effects of $\mathrm{PAR}_{2}$ agonists on chloride secretion, mucus secretion in the gastro-intestinal tract, or coronary vasodilatation, were mediated by a mechanism involving activation of C-fibers (Green et al. 1999, Kawabata et al. 2001, McLean et al. 2002). These results suggest that direct activation of $\mathrm{PAR}_{2}$ on sensory neurons, and particularly on C-fibers, is responsible for different pathophysiological changes associated with inflammation, including a neurogenic inflammatory response.

$\mathrm{PAR}_{1}$ was also found present on sensory neurons (de Garavilla et al. 2001), but its activation failed to release neuropeptides in the different tissues observed. However, neuropeptide receptor antagonists were able to significantly reduce PAR 1 agonist-induced oedema (de Garavilla et al. 2001). Taken together, these results suggest that $\mathrm{PAR}_{1}$ activation leads to inflammation through a pathway that involves a neurogenic mechanism that might be indirectly activated after $\mathrm{PAR}_{1}$ activation. The role of $\mathrm{PAR}_{1}$ activation in inflammation seems to be linked to activation of $\mathrm{PAR}_{1}$ on other cell types than sensory neurons.

$\mathrm{PAR}_{4}$ was also found present on peripheral neurons (D'Andrea et al. 2003). However, the functionality of $\mathrm{PAR}_{4}$ on those cells has never been investigated.

\section{Involvement of $\mathbf{P A R}_{2}$ activation in inflammatory hyperalgesia}

The presence and functionality of $\mathrm{PAR}_{2}$ on sensory neurons led us to investigate whether or not PAR ${ }_{2}$ activation was implicated in inflammatory nociceptive pathways. Since PAR $_{2}$ agonists caused inflammation, we first defined doses of PAR 2 agonists that did not cause any signs of inflammation, by following oedema, granulocyte recruitment, prostaglandin release and blood flow (Vergnolle et al. 2001a). Then, we used this sub-inflammatory dose to investigate whether or not it was capable of inducing hyperalgesia in response to a thermal or mechanical stimulation. Intraplantar injection of $\mathrm{PAR}_{2}$-activating peptide, trypsin or mast cell tryptase at doses that did not cause inflammation, provoked thermal and mechanical hyperalgesia. The same injections also caused activation of nociceptors at the spinal level, as followed by an increased fos expression in the superficial laminae (I and II) of the dorsal horn (Vergnolle et al. 2001a). Moreover, this study showed that $\mathrm{PAR}_{2}$-deficient mice developed significantly less inflammatory hyperalgesia in response to intraplantar injection of formalin or the mast cell degranulator compound 48/80 (Vergnolle et al. 2001a). The $\mathrm{PAR}_{2}$ agonistmediated hyperalgesia was dependent on a mechanism involving central activation of neurokinin-1 receptors, release of pre-pro tachykinins and release of prostaglandins (Vergnolle et al. 2001a). More recently, we have shown that activation of $\mathrm{PAR}_{2}$ was able to potentiate responses of TRPV1 receptors to capsaicin (Amadesi et al. 2004). In that study, we showed through both a pharmacological and gene-deletion approach that TRPV1 was implicated in $\mathrm{PAR}_{2}$-induced thermal hyperalgesia. We showed that $\mathrm{PAR}_{2}$-induced thermal hyperalgesia was inhibited by the TRPV1 antagonist capsazepine, and completely abolished in TRPV1-deficient mice, while $\mathrm{PAR}_{2}$-induced mechanical hyperalgesia was not changed by TRPV1 deficiency or antagonist treatments. Further, this study showed that TRPV1 activation in dorsal root ganglia neurons was po- 
tentiated by pre-exposure of those neurons to $\mathrm{PAR}_{2}$ agonists, and this potentiating mechanism was PKC-dependent (Amadesi et al. 2004). Other studies also suggest the involvement of $\mathrm{PAR}_{2}$ in visceral pain (Hoogerwerf et al. 2001, Coelho et al. 2002). Colonic or pancreatic activation of $\mathrm{PAR}_{2}$ was shown to be responsible for activation of nociceptors at a spinal level and in the case of colon, $\mathrm{PAR}_{2}$ agonists were able to induce long-lasting visceral hyperalgesia. In vitro studies showing that activation of $\mathrm{PAR}_{2}$ on peripheral neurons provoked calcium mobilization (Steinhoff et al. 2000), but also long-lasting hyperexcitability (Reed et al. 2003), suggest that the hyperalgesic effects of PAR $\mathrm{P}_{2}$ agonists are due to the direct activation of the receptor on sensory neurons. However, the fact that $\mathrm{PAR}_{2}$ agonists provoke the release of different mediators (prostaglandins, cytokines, etc.) in different cell types (endothelial cells, leukocytes, etc.) needs also to be considered in the context of inflammatory pain. PAR activation might also participate to inflammatory pain by inflammatory mediators-induced sensitization of sensory neurons.

\section{Thrombin receptor activation: new analgesic pathways?}

Peripheral activation (intraplantar injections) by thrombin or a selective activating peptide of the thrombin receptor $\mathrm{PAR}_{1}$, provoked an increase in nociceptive threshold to thermal and mechanical stimulus (Asfaha et al. 2002). This anti-nociceptive effect observed in basal conditions was reproduced in inflammatory conditions after carrageenan intraplantar injection (Asfaha et al. 2002). Another study has shown recently that spinal activation of $\mathrm{PAR}_{1}$ inhibited NMDA-induced nociceptive activity through a mechanism dependent on endothelin A (Fang et al. 2003). Because $\mathrm{PAR}_{1}$ activation on sensory neurons causes calcium mobilization, one can doubt that $\mathrm{PAR}_{1}$ agonists exert their anti-nociceptive effects by direct activation of sensory fibers. Further studies on the signaling pathways and electrical responses of sensory neurons to PAR $_{1}$ agonists are needed to fully understand such mechanism.

\section{Conclusions}

Studies have shown that $\mathrm{PAR}_{1}, \mathrm{PAR}_{2}$ and $\mathrm{PAR}_{4}$ are present on peripheral neurons. The fact that $\mathrm{PAR}_{2}$ activation can induce neurogenic inflammation and participate to the generation of inflammatory pain present $\mathrm{PAR}_{2}$ as a valuable target for the treatment of inflammation and pain (Fig. 2). PAR 1 activation also leads to inflammation with a neurogenic component. However, PAR $_{1}$ activation is also associated with analgesic response and inhibition of inflammatory hyperalgesia, presenting $\mathrm{PAR}_{1}$ as a mediator that could exert dual activity in inflammatory pain mechanisms.

In conclusion, it appears that recent advances in basic science pointed to a crucial role for proteinases and their receptors in inflammatory hyperalgesia. We need to consider proteinases not only as digestive or degradative enzymes, but as signalling molecules that actively participate to several clinical symptoms associated with inflammatory diseases.

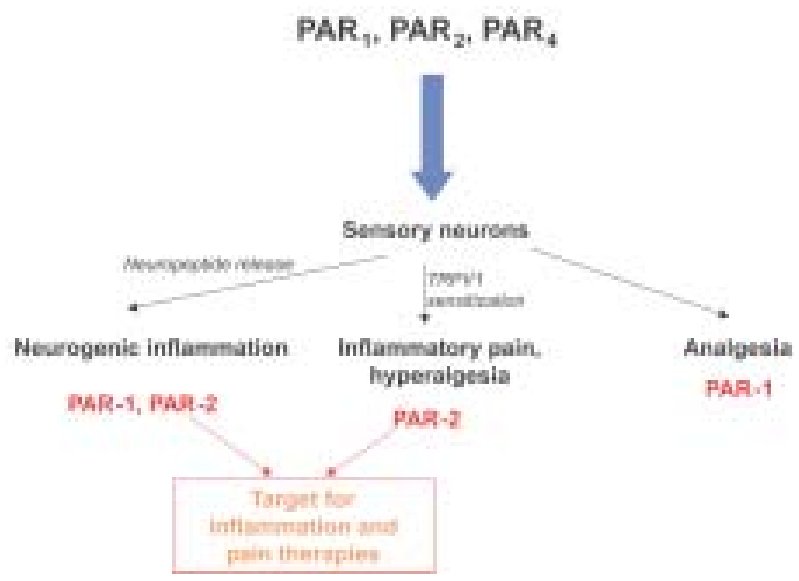

Fig. 2: signals of proteinase-activated receptors, $\mathrm{PAR}_{1}, \mathrm{PAR}_{2}$ and $\mathrm{PAR}_{4}$ activation to sensory neurons and their known pathophysiological consequences. Activation of $\mathrm{PAR}_{2}$ on sensory neurons leads to neurogenic inflammation through the release of neuropeptides, and to pain and hyperalgesia through the sensitization of TRPV1 receptor, thus highlighting $\mathrm{PAR}_{2}$ as an interesting target for inflammation and pain therapies. $\mathrm{PAR}_{1}$ activation on sensory neurons also provokes a neurogenic inflammation in certain tissues, through the release of neuropeptide, but low doses of PAR agonists inhibit inflammatory hyperalgesia and caused analgesia, thereby suggesting dual and opposite effects in inflammation and pain.

\section{REFERENCES}

Amadesi S, Nie J, Vergnolle N, Cottrell GS, Grady EF, Trevisani M, Manni C, Geppetti P, McRoberts JA, Ennes H, Davis JB, Mayer EA, Bunnett NW 2004. Protease-activated receptor 2 sensitizes the capsaicin receptor transient receptor potential vanilloid receptor 1 to induce hyperalgesia. J Neurosci 24: 4300-4312.

Asfaha S, Brussee V, Chapman K, Zochodne DW, Vergnolle N 2002. Proteinase-activated receptor-1 agonists attenuate nociception in response to noxious stimuli. Br J Pharmacol 135: 1101-1106.

Cenac N, Coelho A, Nguyen C, Compton S, Andrade-Gordon P, Macnaughton WK, Wallace JL, Hollenberg MD, Bunnett NW, Garcia-Villar R, Bueno L, Vergnolle N 2002. Induction of intestinal inflammation in mouse by activation of Proteinase-Activated Receptor-2. Am J Pathol 161: 1903-1915.

Cirino G, Cicala C, Bucci M, Sorrentino L, Maraganore J, Stone S 1996. Thrombin functions as an inflammatory mediator through activation of its receptor. J Exp Med 183: 821-827.

Cocks TM, Fong B, Chow JM, Anderson GP, Frauman AG, Goldie RG, Henry PJ, Carr MJ, Hamilton JR, Moffatt JD 1999. A protective role for protease-activated receptors in the airways. Nature 398: 156-160.

Coelho AM, Vergnolle N, Guiard B, Fioramonti J, Bueno L 2002. Proteinases and proteinase-activated receptor 2: a possible role to promote visceral hyperalgesia in rats. Gastroenterology 122: 1035-1047.

D'Andrea MR, Sabam MR, Nguyen NB, Andrade-Gordon P, Saban R 2003. Overriding participation of protease activated receptor (PAR)s 1, 2, 3, and 4 in experimental bladder inflammation. Am J Pathol 162: 907-923.

de Garavilla L, Vergnolle N, Young SH, Ennes H, Steinhoff M, 
Ossovskaya VS, D'Andrea MR, Mayer EA, Wallace JL, Hollenberg MD, Andrade-Gordon P, Bunnett NW 2001. Agonists of proteinase-activated receptor 1 induce plasma extravasation by a neurogenic mechanism. Br J Pharmacol 133: 975-987.

Fang M, Kovacs KJ, Fisher LL, Larson AA 2003. Thrombin inhibits NMDA-mediated nociceptive activity in the mouse: possible mediation by endothelin. J Physiol 549: 903-917.

Ferrell WR, Lockhart JC, Kelso EB, Dunning L, Plevin R, Meek SE, Smith AJ, Hunter GD, McLean JS, McGarry F, Ramage R, Jiang L, Kanke T, Kawagoe J 2003. Essential role for proteinase-activated receptor-2 in arthritis. $J$ Clin Invest 111: 35-41.

Fiorucci S, Mencarelli A, Palazzetti B, Distrutti E, Vergnolle N, Hollenberg MD, Wallace JL, Morelli A, Cirino G 2001. Proteinase-activated receptor 2 is an anti-inflammatory signal for colonic lamina propria lymphocytes in a mouse model of colitis. Proc Natl Acad Sci USA 98: 13936-13941.

Green BT, Bunnett NW, Brown DR 1999. Type 2 proteaseactivated receptor (PAR-2) in porcine ileal mucosa. Neuroregulation of active ion transport and modulation by d-opiod receptors. FASEB J 13: A733.

Hollenberg MD, Saifeddine M, Sandhu S, Houle S, Vergnolle N 2004. Proteinase-activated receptor-4: evaluation of tethered ligand-derived peptides as probes for receptor function and as inflammatory agonists in vivo. Br J Pharmacol 143: 443-454.

Hoogerwerf WA, Zou L, Shenoy M, Sun D, Micci MA, LeeHellmich H, Xiao SY, Winston JH, Pasricha PJ 2001. The proteinase-activated receptor 2 is involved in nociception. J Neurosci 21: 9036-9042.

Kawabata A, Kinoshita M, Nishikawa H, Kuroda R, Nishida M, Araki H, Arizono N, Oda Y, Kakehi K 2001. The protease-activated receptor-2 agonist induces gastric mucus secretion and mucosal cytoprotection. J Clin Invest 107: $1443-1450$

McLean PG, Aston D, Sarkar D, Ahluwalia A 2002. Proteaseactivated receptor-2 activation causes EDHF-like coronary vasodilation: selective preservation in ischemia/reperfusion injury: involvement of lipoxygenase products, VR1 receptors, and C-fibers. Circ Res 90: 465-472.

Reed DE, Barajas-Lopez C, Cottrell G, Velazquez-Rocha S, Dery O, Grady EF, Bunnett NW, Vanner S 2003. Mast cell tryptase and proteinase-activated receptor 2 induce hyperexcitability of guinea pig submucosal neurons. J Physiol 547: 531-542.

Schmidlin F, Amadesi S, Dabbagh K, Lewis DE, Knott P, Bunnett NW, Gater PR, Geppetti P, Bertrand C, Stevens ME 2002. Protease-activated receptor 2 mediates eosinophil infiltration and hyperreactivity in allergic inflammation of the airway. J Immunol 169: 5315-5321.

Seeliger S, Derian CK, Vergnolle N, Bunnett NW, Nawroth R, Schmelz M, Der Weid PY, Buddenkotte J, Sunderkotter C, Metze D, Andrade-Gordon P, Harms E, Vestweber D, Luger TA, Steinhoff M 2003. Proinflammatory role of proteinase-activated receptor- 2 in humans and mice during cutaneous inflammation in vivo. FASEB J 17: 1871-1885.

Steinhoff M, Vergnolle N, Young S, Tognetto M, Amadesi S, Ennes H, Trevisani M, Hollenberg MD, Wallace JL, Caughey G, Mitchell S, Williams L, Geppetti P, Mayer E, Bunnett N 2000. Agonists of proteinase-activated receptor 2 induce inflammation by a neurogenic mechanism. Nat Med 6:151158.

Vergnolle N 1999. Proteinase-activated receptor-2-activating peptides induce leukocyte rolling, adhesion, and extravasation in vivo. J Immunol 163: 5064-5069.

Vergnolle N 2000. Review article: proteinase-activated receptors-novel signals for gastrointestinal pathophysiology. Aliment Pharmacol Ther 14: 257-266.

Vergnolle N, Hollenberg MD, Wallace JL 1999b. Pro- and antiinflammatory actions of thrombin: a distinct role for proteinase-activated receptor-1 (PAR1). Br J Pharmacol 126: 1262-1268.

Vergnolle N, Bunnett NW, Sharkey KA, Brussee V, Compton S, Grady EF, Cirino G, Gerard N, Basbaum A, Andrade-Gordon P, Hollenberg MD, Wallace JL 2001a. Proteinase-activated receptor-2 and hyperalgesia: a novel pain pathway. Nat Med 7: 821-826.

Vergnolle N, Hollenberg MD, Sharkey K, Wallace JL 1999a. Characterization of the inflammatory response to proteinase-activated receptor-2 (PAR-2)-activating peptides in the rat paw. Br J Pharmacol 127: 1083-1090.

Vergnolle N, Wallace JL, Bunnett NW, Hollenberg MD 2001b. Protease-activated receptors in inflammation, neuronal signaling and pain. Trends Pharmacol Sci 22: 146-152. 